University of New Hampshire

University of New Hampshire Scholars' Repository

4-30-2003

\title{
Remotely forced nearshore upwelling in southern California
}

James M. Pringle

University of New Hampshire, James.Pringle@unh.edu

K Riser

University of California - San Diego

Follow this and additional works at: https://scholars.unh.edu/earthsci_facpub

Part of the Earth Sciences Commons

\section{Recommended Citation}

Pringle, J. M., and K. Riser, Remotely forced nearshore upwelling in Southern California, J. Geophys. Res., 108(C4),3131

This Article is brought to you for free and open access by the Earth Sciences at University of New Hampshire Scholars' Repository. It has been accepted for inclusion in Earth Sciences Scholarship by an authorized administrator of University of New Hampshire Scholars' Repository. For more information, please contact Scholarly.Communication@unh.edu. 


\title{
Remotely forced nearshore upwelling in Southern California
}

\author{
James M. Pringle \\ Department of Earth Sciences, University of New Hampshire, Durham, New Hampshire, USA
}

\begin{abstract}
Kristin Riser
Integrative Oceanography Division, Scripps Institution of Oceanography, University of California, San Diego, La Jolla, California, USA
\end{abstract}

Received 23 April 2002; revised 10 December 2002; accepted 5 February 2003; published 30 April 2003.

[1] Alongshore winds in Baja California strongly influence nearshore temperatures hundreds of kilometers to the north at Point Loma, San Diego, California, on timescales of a week to a year. The time lag between wind and temperature is consistent with first mode coastal trapped wave phase speed. The nearshore cross-shelf circulation forced by the coastal trapped waves is, at least much of the year, oppositely directed at the surface and bottom. No relation is found between the winds and temperature for periods greater than a year. It is argued that similar results may be found elsewhere in the Southern California Bight. The relationship between stratification and bottom temperature varies over the 1.3 years of data, but for much of the time, warmer bottom waters are associated with even warmer surface waters and thus stronger stratification. The effects of the remotely forced cross-shelf exchange on coastal pollution, nutrient dynamics, and larval transport are briefly discussed. INDEX TERMS: 4219 Oceanography: General: Continental shelf processes; 4279 Oceanography: General: Upwelling and convergences; 4546 Oceanography: Physical: Nearshore processes; KEYWORDS: nearshore, upwelling, coastal trapped waves, Southern California Bight, remote forcing

Citation: Pringle, J. M., and K. Riser, Remotely forced nearshore upwelling in Southern California, J. Geophys. Res., 108(C4), 3131, doi:10.1029/2002JC001447, 2003.

\section{Introduction}

[2] San Diego is a region of weak winds and generally mild weather [Lentz and Winant, 1986], and yet observations of the subsurface water temperatures in depths of less than $33 \mathrm{~m}$ show strong episodic temperature events on timescales of days to months. The several degree magnitude of these events is comparable to the annual cycle (Figure 1).

[3] The sudden drops in nearshore (depth $\leq 33 \mathrm{~m}$ ) subsurface temperatures are argued below to represent the onshore transport of cold bottom water and the offshore transport of warmer surface waters. This nearshore crossshelf transport has broad implications for both the biological and pollution dynamics in this region. Cooling events will tend to bring nutrients to the nearshore kelp forests of San Diego, and cooling is well correlated with the health of the kelp forests [Tegner et al., 1996]. The offshore transport of surface water in these cooling events may dilute coastal pollution, preventing or ending the economically harmful beach closures caused by Coliform bacteria. Conversely, sudden warming events are likely correlated with lower nutrients and the trapping of warm, polluted water near the coast. It is shown below that the changes in temperature are associated with changes in stratification. Increases in stratification will decrease vertical mixing, decreasing the vertical transport of heat and nutrients. The changes in

Copyright 2003 by the American Geophysical Union. 0148-0227/03/2002JC001447 stratification will also alter the strength of the internal waves and bores which transport plankton to the nearshore and concentrate depth-keeping plankton in the water column [Pineda, 1999; Pineda and Lopez, 2002; Lennert-Cody and Franks, 1999].

[4] Despite their importance, little is known about the origin of these nearshore temperature fluctuations, for they do not seem to be well correlated with local winds or other local forcing. The work below examines the relationship between the nearshore temperature and the coastal winds of Baja California, hundreds of kilometers to the south.

[5] There is abundant literature describing the generation of low mode coastal trapped waves (CTWs) by winds along the coast of Baja California, Mexico, and their subsequent propagation poleward into the Southern California Bight. Lentz and Winant [1986] found that alongshore pressure gradients associated with Mexican winds strongly affected wintertime currents near San Diego, California, in water depths of 30 and $60 \mathrm{~m}$ at lags consistent with CTWs. Hickey [1992] and Hickey et al. [2003] have shown that alongshore pressure gradients associated with these freely propagating CTWs often dominate currents in the Central Southern California Bight. Poleward traveling CTWs have also been found to be important farther north along the west coast of North America [e.g., Battisti and Hickey, 1984; Chapman, 1987; Denbo and Allen, 1987].

[6] The existing literature does not tend to support a strong link between the remotely forced CTWs and the 


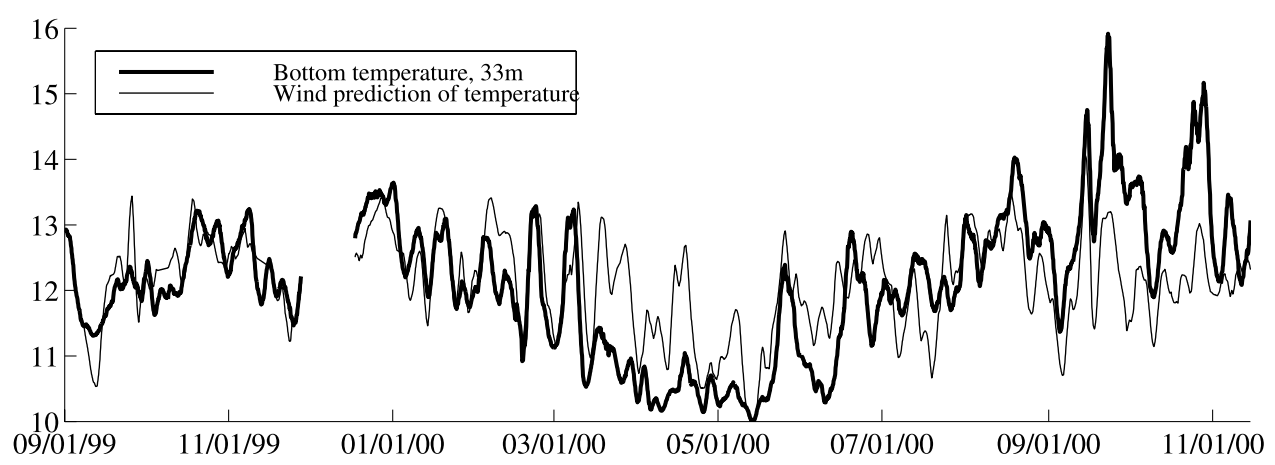

Figure 1. Two-day low-pass filtered bottom temperature on the $33-\mathrm{m}$ isobath near Point Loma (solid line). Prediction of temperature from time-lagged winds at $29.5^{\circ} \mathrm{N}, 26^{\circ} \mathrm{N}$ and $22.3^{\circ} \mathrm{N}$ from equation (2) (thin line).

nearshore temperature. Most past attempts to use coastal trapped wave theory to explain temperature fluctuations have not been very successful, even while the theory has predicted free-surface elevation and alongshore currents well [e.g., Brink, 1982]. Chapman [1987] did find good correlations between expected and predicted nearshore temperature fluctuations in the Coastal Ocean Dynamics Experiment region, but the magnitude of the observed temperature change was much greater than expected. The analysis by Lentz and Winant [1986] of the alongshore momentum balance about $30 \mathrm{~km}$ north of San Diego found that remote forcing was not dominant in the nearshore; it was weaker than local forcing on the $15-\mathrm{m}$ isobath and comparable to local forcing on the $30-\mathrm{m}$ isobath.

[7] Theoretical work on remote coastal forcing and coastal trapped waves (CTWs) has either tended to ignore the nearshore, or argue that it is unaffected by remote forcing because of the dominance of friction in the nearshore. Past analyses have also assumed that frictional boundary layers are thin and unaffected by the horizontal transport of buoyancy, assumptions which are unlikely to be simultaneously true in the 10 - to 30 -m-deep nearshore waters considered below [Brink and Allen, 1978]. Most CTW work has assumed a coastal wall to exist at a depth of about $30 \mathrm{~m}$, and have justified this with Mitchum and Clarke's [1986] argument that this wall would not affect the offshore CTW structure. Steady-state arguments based on Csanady's arrested topographic wave theory, valid for weak stratification, also suggest that the effects of the remote forcing will be confined to the outer parts of the shelf [Winant, 1979; Pringle, 2002].

[8] Nonetheless, it is shown below that the water temperature over the 15- and 33-m isobaths in the waters off Point Loma, San Diego, are correlated with winds hundreds of kilometers to the south at phase lags consistent with first mode CTW phase speeds on timescales from several days to a year. Following is a brief discussion of possible physical mechanisms linking the CTWs to the nearshore temperatures and the possible role of the sudden changes in shelfwidth near Point Loma in enhancing the influence of CTWs on temperature.

[9] Because of the scarcity of data, these discussions will be necessarily tentative. It will be argued, however, that remote winds drive an upwelling/downwelling circulation near Point Loma and that the temperature variation is unlikely to be dominated by inertial or cyclostrophic dynamics driven by coastline curvature. This suggests that the nearshore temperature variation does not depend critically on the peculiar geometry of Point Loma, and thus that a similar link between Mexican winds and nearshore temperature may exist elsewhere in the Southern Californian Bight.

\section{Data Sources}

[10] Temperature data are obtained in and offshore of the Point Loma kelp forest as part of the SIO kelp forest project. Temperatures have been measured from moorings since late 1997 on the 33-m isobath and since 1984 on the $15-\mathrm{m}$ isobath with ONSET Stowaway temperature loggers (Figure 2). The temperature was measured every $10 \mathrm{~min}$ after 1997 and every hour before then, with an accuracy of $0.2^{\circ} \mathrm{C}$ and a resolution of $0.15^{\circ} \mathrm{C}$. Because prior work in the Southern Californian Bight has shown temperature to dominate the variability of the density field, the contribution of salinity to density variation will be neglected [Winant and Bratkovitch, 1981]. All temperature time series used below have been low-pass filtered with a 2-day boxcar filter. (The 2-day boxcar filter was chosen since it reasonably suppresses $M_{2}$ internal tidal signals and can also be applied as is to the 12-hourly wind data described below.) Analysis will focus on temperatures 0,18 and $26 \mathrm{~m}$ above the bottom on the $33-\mathrm{m}$ isobath and on the bottom at the $15-\mathrm{m}$ isobath.

[11] Most analysis will be made with wind data obtained by the QuikSCAT scatterometer. The satellite was launched in July of 1999, and the 12-hourly, $0.5^{\circ}$ global gridded wind data are released in near real time from JPL (the data are obtained from the NASA/NOAA sponsored data system Seaflux at JPL, through the courtesy of W. Timothy Liu and Wenqing Tang). The wind data are corrupted near land, so data are only available to within $0.5^{\circ}$ of land. All wind data discussed below has been low-pass filtered with a 2-day boxcar filter. Most analysis has been confined to data from September 1999 through December 2000, to coincide with the availability of JPL Seaflux QuikSCAT 12-hourly wind data.

[12] The satellite data compare reasonably well with lowpass filtered buoy data from buoys far enough offshore that they lie under valid satellite data. Regional winds from NDBC buoy 46047 , at $32.43^{\circ} \mathrm{N}$ and $119.53^{\circ} \mathrm{W}$ (west of San 


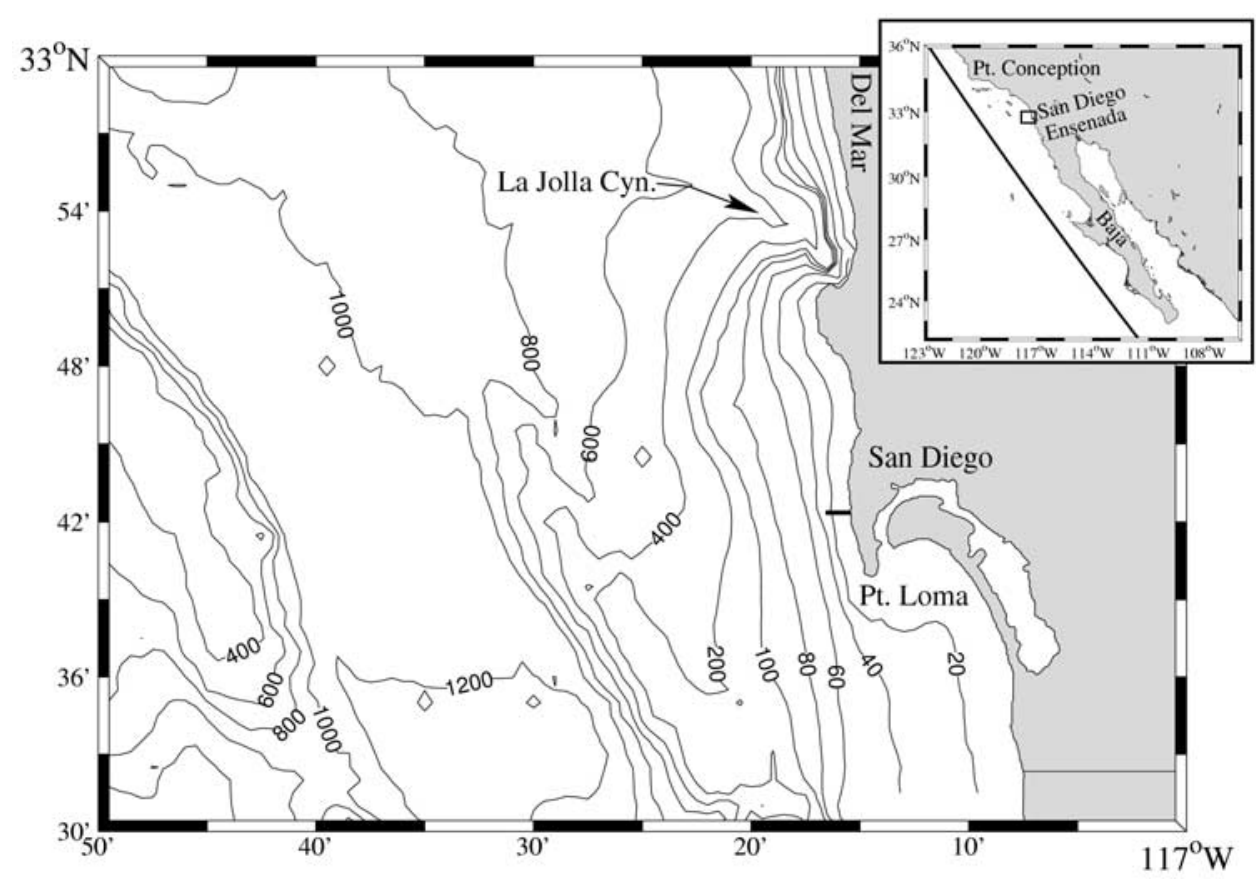

Figure 2. Map of San Diego/Point Loma area with isobaths marked in meters. The thick line protruding from Point Loma indicates the location of 15-, 22- and 33-m moorings. The location of small-scale map is indicated by a box on the inset large-scale map. The location of the winds used in the paper is given by the alongshore line on the large-scale map and equations (1a)-(1c).

Diego and South of the Channel islands), have a vector correlation with the satellite winds of $0.6(\mathrm{P}>0.99)$, and the satellite winds are about $10 \%$ stronger than the buoy winds (the vector correlation is computed following Kundu [1976], and a perfect correlation would be 1). There is some evidence that these comparisons improve slightly for stronger winds. There is a persistent angular offset of about $15-20^{\circ}$ between Southern Californian Bight NDBC buoys and the satellite winds, with the buoy winds counterclockwise from the satellite winds. Freilich and Dunbar [1999] find similar results in an extensive comparison of NSCAT winds to NDBC buoys. The satellite data were not fit to or calibrated by the Californian NDBC buoy data, so the wind data should be as accurate near Baja California.

[13] More serious than the errors in the satellite wind data are the lack of coverage at the coast. North of Point Conception, this does not seem to be a problem, as the coastal NDBC buoys there correlate well and most strongly with the closest offshore satellite data. South of Point Conception, however, the maximum correlation to the buoy winds is not with the satellite winds immediately offshore, but with the satellite winds nearest to the shore $2-3^{\circ}$ to the south. For example, the Scripps Institution of Oceanography (SIO) pier winds http://cdip.ucsd.edu/), taken near the shore in La Jolla, California, at $33^{\circ} \mathrm{N}$, are most correlated with the satellite winds closest to shore between 30 and $31^{\circ} \mathrm{N}$. The correlation $(\mathrm{r}=0.45, \mathrm{P}>0.95)$ is weaker than between collocated buoy and satellite measurements, and the Scripps Pier winds are rotated about $30^{\circ}$ counterclockwise from the satellite winds. The correlation is best at near zero time lag. This spatially lagged correlation will have to be accounted for when we argue that the nearshore temperature at San
Diego is most strongly affected by the alongshore winds to the south of San Diego, and not those at San Diego.

[14] It will be assumed below that the satellite winds offshore of Baja California are most correlated to the coastal winds immediately shoreward, as is true north of Point Conception. Consistent with this, Winant and Dorman [1997] find that the region of anomalous winds caused by the bend in the coast at Point Conception is confined inshore of a line which extends from Point Conception to Ensenada, Mexico (inset of Figure 2). There is little in situ wind data to confirm this assumption; however, it is supported by an analysis of winds modeled by the $27-\mathrm{km}$ resolution COAMPS mesoscale meteorological model from the Navy Research Laboratory's marine meteorological division (model description given by Hodur [1997]). The model wind data extend northward of $29^{\circ} \mathrm{S}$, and 12-hourly data are publicly available. The model winds compare to collocated NDBC buoys nearly as well as the satellite winds. Several analyses will be repeated with the model winds and shown below to confirm that the results are not artifacts of the scatterometer or its inability to sample near land.

[15] The satellite wind data, and the high-resolution numerical model winds, do not extend to earlier than 1999. To examine the relation between winds and the 16year record of bottom temperature at $15 \mathrm{~m}$, the National Center for Environmental Predictions and the National Center for Atmospheric Research (NCAR/NCEP) reanalysis winds will be used [Kalnay et al., 1996]. These winds have a coarse $2.5^{\circ}$ resolution, but are available over the entire temperature time series, and will be shown to capture the important details of the remote wind forcing. Over the time 


\section{Correlation between remote winds and temperature bottom on $33 \mathrm{~m}$ isobath}

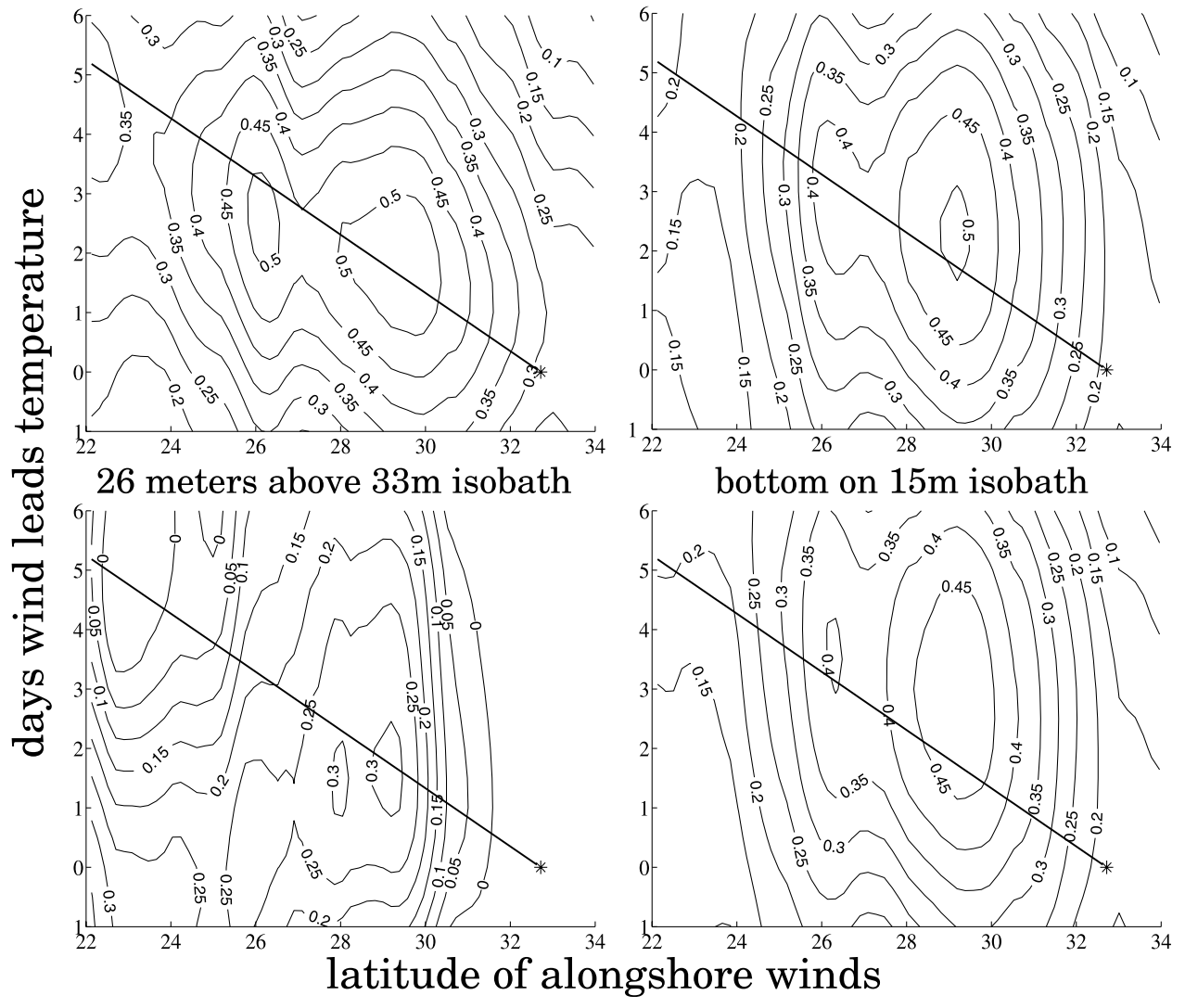

Figure 3. Correlation between time-lagged alongshore winds at latitudes from $22^{\circ} \mathrm{N}$ to $34^{\circ} \mathrm{N}$ and water temperature at four locations. The asterisk marks the location of San Diego at zero time lag. Any correlation greater than 0.16 is significantly different from zero at the $95 \%$ level. The solid line indicates the phase speed of a mode 1 coastal trapped wave.

period analyzed, the NCAR/NCEP winds did not include scatterometer data from QuikSCAT.

[16] Since several wind products, each with different spatial organization, are used, it is convenient to interpolate the winds to a common line (Figure 2),

$$
\begin{gathered}
g=0 \text { to } 1.65 \\
\text { longitude }=248.45-9 g \\
\text { latitude }=22.13+11.07 g .
\end{gathered}
$$

The positive "alongshore" direction is defined to be northward along this line, and is on average $19.93^{\circ}$ counterclockwise from true north. To examine the impact of interpolating to this line, the results below were recalculated with the valid winds closest to shore for the several wind products. No significant changes in the results presented below were found. Trying to adjust the "alongshore" orientation at each point along the shore to conform to the local shoreline orientation did not improve the results, nor was it clear how to choose the orientation correctly and unambiguously when comparing wind products on different grids, especially given the uncertain offshore lengthscale of local orographic effects. A pseudo-stress, whose amplitude is the square of the winds amplitude and whose direction is the same as the winds, was calculated from the winds on the line defined above and used for the analysis below.

\section{Data Analysis}

[17] The water temperature at $33 \mathrm{~m}$ depth on the bottom near the Point Loma kelp forest was lag-correlated with the alongshore pseudo-stress from the QuikSCAT satellite (Figure 3), and the strongest correlations were found with the winds to the south at a temporal lag which increases roughly linearly with distance to the south. The maximum correlation of $r=0.53$ is at $29.5^{\circ} \mathrm{N}$ with the wind leading the temperature by about 1.75 days, and at $26^{\circ} \mathrm{N}$, there is a statistically indistinguishable secondary maximum with the wind leading the temperature by 2.5 days. The winds decorrelate over 5 days, so any correlation over 0.16 is significant at $P>0.95$. For comparison, a line representing the $2.8 \mathrm{~m} \mathrm{~s}^{-1}$ phase speed of a mode one CTW south of San Diego has been included in Figure 3 (phase speed from Battisti and Hickey [1984], coastline section 8). The agreement between CTW phase line and the region of maximum correlation is good [cf. Allen and Denbo, 1984]. Qualita- 
$33 \mathrm{~m}$ bottom temperature vrs. lagged alongshore wind

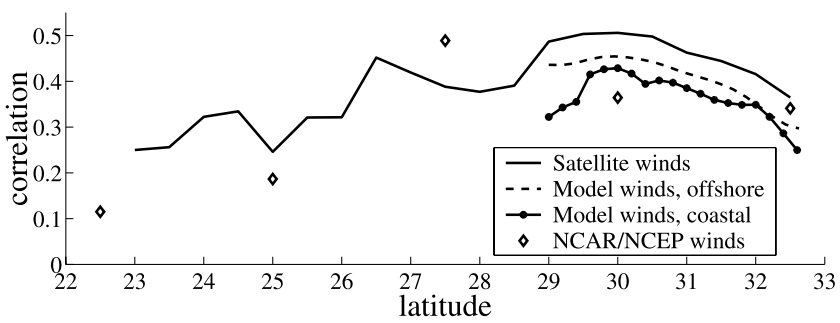

Figure 4. Correlation between the time-lagged alongshore winds and bottom temperature on the 33-m isobath for scatterometer winds, winds from the COAMPS model at the same location as the satellite winds, winds from the COAMPS model at the coast, and winds from the $2.5^{\circ}$ NCAR/NCEP reanalysis. The winds are lagged by a time appropriate to the phase speed of a mode 1 CTW.

tively similar results are found when the temperature is compared to the alongshore winds from the COAMPS model, using either the model winds taken at the same location as the satellite winds or the winds immediately adjacent to the coast (Figure 4). The spatial and temporal autocorrelation of the winds is shown in Figure 5c.

[18] The results of a similar comparison between the wind and the temperature at the bottom on the $15-\mathrm{m}$ isobath, and between the wind and the temperature $18 \mathrm{~m}$ off the $33-\mathrm{m}$ isobath, are quite similar, with a nonsignificantly reduced $(r \approx 0.5)$ correlation and a half day longer lag $18 \mathrm{~m}$ above the 33-m isobath and a day longer on the $15-\mathrm{m}$ isobath. A similar analysis for temperature $6 \mathrm{~m}$ from the surface over the 33-m isobath shows a much reduced, though still significant, lagged correlation. It will be shown below that the behavior of the surface temperature changes over the study period. The phase lag between the shallower and deeper temperatures on the $33-\mathrm{m}$ isobath is consistent with the observations of Hickey et al. [2003] at greater depths; the phase lag of the inshore data from the offshore data is not consistent, nor does it agree with theoretical predictions of frictionally modified CTWs [Brink, 1982].

[19] It is necessary to argue that the observed correlation between the temperature and the remote winds is not an artifact of the correlation between the local and remote winds. Winds from the SIO pier, about $15 \mathrm{~km}$ to the north of Point Loma, were low-pass filtered in the same manner as the satellite winds and compared to the water temperature. The maximum correlation of 0.35 was between nearly onshore winds and cooling of the middle and lower water column temperature at 15 and $33 \mathrm{~m}$ depth. The onshore wind led the cooling by about 1.5 to 2.5 days. Figure $5 \mathrm{a}$ shows the lagged correlation between the cross-shelf wind at the SIO pier and the alongshore satellite winds. The onshore pier winds are most correlated with alongshore satellite winds in roughly the same locations that the correlation between the remote winds and temperature is greatest. The local cross-shelf wind leads the remote alongshelf wind by about half a day, regardless of the distance of
A)

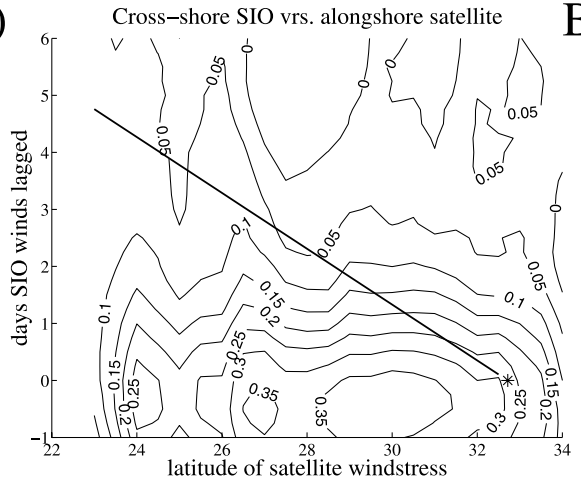

C)

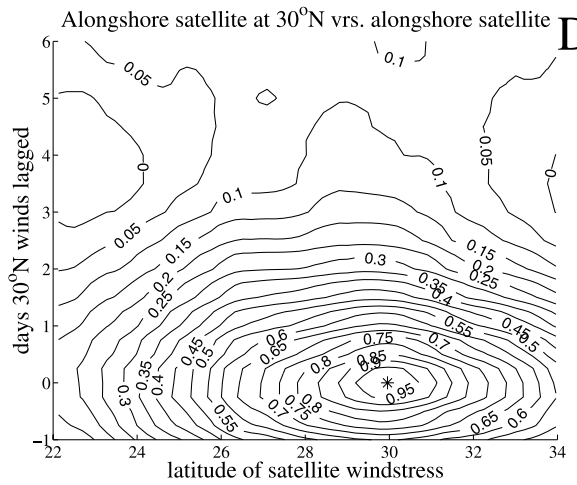

B)
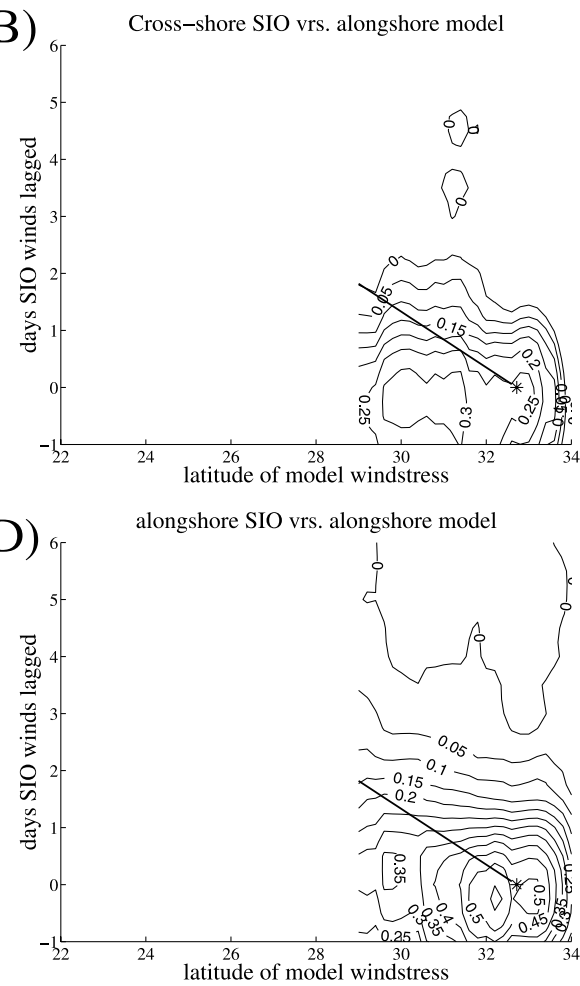

Figure 5. (a) Lagged correlation of the onshore wind at the Scripps Institute of Oceanography pier with the alongshore satellite winds from $22^{\circ} \mathrm{N}$ to $34^{\circ} \mathrm{N}$. (b) as Figure 5 a but with alongshore COAMPS winds at the coastline. (c) Lagged correlation for alongshore satellite wind at $30^{\circ} \mathrm{N}$ with the alongshore satellite winds from $22^{\circ} \mathrm{N}$ to $34^{\circ} \mathrm{N}$. (d) as in Figure 5a but with alongshore COAMPS winds at the coastline and alongshore SIO pier winds. 
the remote wind from SIO. This correlation structure is not an artifact of the satellite winds being measured offshore of the coast: Similar correlation structure is seen between the alongshore winds at the coast from the COAMPS model and the cross-shore SIO pier winds (Figure 5b). For comparison, the correlation between the alongshore SIO pier winds and the alongshore COAMPS winds are included in Figure $5 \mathrm{~d}$.

[20] There are three reasons to believe that the nearshore temperature is controlled by the remote alongshore winds, and not the local cross-shore winds. The first is the existence of a time lag between the remote alongshore winds and the local temperature which increases nearly linearly with the distance of the winds from San Diego (Figure 3). This differs from the correlation between the remote and local winds, which is maximum at the same time lag, regardless of the distance of the remote winds from San Diego. Since the spectra of the satellite winds do not vary greatly in shape as a function of latitude, there is no reasonable differential equation forced by the local crossshelf winds whose solution would have a maximum correlation with the satellite winds at a lag which increases linearly with the distance of the satellite winds from San Diego. The increase in the lag of maximum correlation with distance strongly indicates that the water temperature is forced by the alongshore winds to the south, not the local winds.

[21] The plausibility of the dynamics involved also support the primacy of the remote forcing. Remote upwellingfavorable winds are associated with nearshore cooling, especially near the bottom and at mid-depth. Despite the uncertainties in the exact mechanism (discussed below), this relation seems plausible. The local wind most correlated with water cooling near the bottom and at mid-depth is an onshore wind. This makes little sense in either a rotationally or frictionally dominated nearshore. Lastly, the magnitude of the correlation coefficient between the remote alongshore winds and local temperature $(0.53)$ is significantly greater than that between the local winds and temperature $(0.35)$ ( $P>0.95$ for 90 degrees of freedom).

[22] For these three reasons, it is most plausible to assume that the variability in the nearshore temperatures at Point Loma are controlled by the winds to the south. Because of the correspondence between the lags of maximum correlation and the predicted phase speed of a first mode CTW, it is reasonable to assume that CTWs are the agents linking the Mexican winds to San Diego's nearshore water temperature.

[23] From the 1.3-year time series of satellite, model winds and temperature analyzed above, it is difficult to determine the timescales over which the remote winds affect local temperature. However, the time series of temperature on the $15-\mathrm{m}$ isobath extends back to 1984 and the NCAR/NCEP reanalysis winds are available for this same time period. The reanalysis winds are on a coarse $2.5^{\circ}$ grid, but as can be seen in Figure 4 where they are compared to the $33-\mathrm{m}$ bottom temperatures over the same time period as the previous analysis, the NCAR/NCEP winds capture the essential details of the remote forcing. The $27.5^{\circ} \mathrm{N}$ alongshore winds are most correlated to the local temperatures, while the winds at 25 and $30^{\circ} \mathrm{N}$ are less so [cf. Hickey et al., 2003]. The overall agreement between the alongshore pseudo-stress at $27.5^{\circ} \mathrm{N}$ and the bottom temperature at

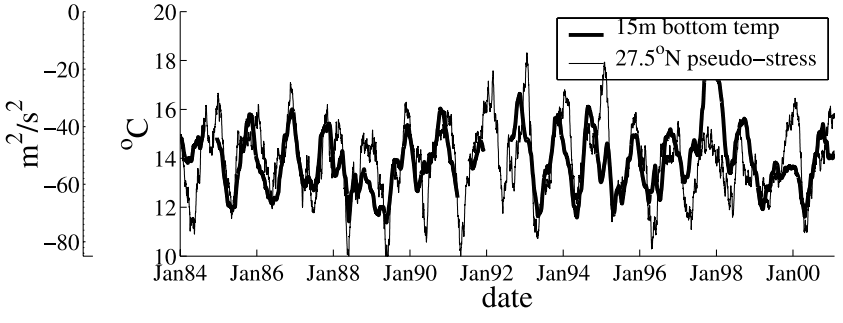

Figure 6. The bottom temperature on the $15-\mathrm{m}$ isobath and the alongshore pseudo-stress at $27.5^{\circ} \mathrm{N}$ from the NCAR/NCEP winds. Both time series have been low-pass filtered to remove variability at periods less than 60 days.

$15 \mathrm{~m}$ is good (Figure 6). The NCAR/NCEP winds at $27.5^{\circ} \mathrm{N}$ and the temperature are then band-pass filtered over various time bands and lag correlated against each other as above. The correlations for each band at the time lag predicted by CTW theory are shown in Table 1 . The correlation is weak but significant for periods of only several days, but quickly increases for longer time periods, except for the greater-than-1-year band. At timescales longer than a year, there is no significant correlation between the wind and the temperature. (The times when the temperature is more than $0.5^{\circ} \mathrm{C}$ above normal for more than a year (early 1997 to late 1998) and below normal (early 1988 to late 1989 and early 1999 to mid-2000) do correspond to large negative and positive fluctuations in the Southern Oscillation Index, as one would expect [Bograd et al., 2001].)

[24] From the remote lagged alongshore winds an estimate of the nearshore bottom temperature at San Diego can be made. Since the winds have a large decorrelation lengthscale, it only makes sense to use the winds at a few locations (Figure 5c). Somewhat arbitrarily, three evenly spaced points between the location of maximum correlation and the tip of Baja were chosen, and a best fit between the lagged alongshore satellite winds at those points and the bottom temperature at the $33-\mathrm{m}$ isobath was made. The lags are those predicted for the phase speed of a mode 1 CTW wave by Battisti and Hickey [1984] for this area, $2.8 \mathrm{~m} \mathrm{~s}^{-1}$, and not the lags of maximum correlation in Figure 3 . The best fit between temperature and the remote alongshore pseudostress $\tau^{p}$ is

$$
\begin{aligned}
T= & 0.019 \tau^{p}\left(29.5^{\circ} \mathrm{N} \text { lagged } 1.54 \text { days }\right) \\
& +0.007 \tau^{p}\left(26^{\circ} \mathrm{N} \text { lagged } 3.22 \text { days }\right) \\
& +0.015 \tau^{p}\left(22.3^{\circ} \mathrm{N} \text { lagged } 5.09 \text { days }\right)+13.74
\end{aligned}
$$

and the correlation between this and the observed temperature is 0.66 (Figure 1). This correlation is not improved if the lags of maximum correlation in Figure 3 are used. Visually, it appears that the transfer coefficient between windstress and temperature is less between April 2000 and May 2000. As will be discussed below, the reason for this is unclear, as it seems unrelated to the local stratification and other observed parameters.

\section{Local Response to Coastal Trapped Waves}

[25] From the data and arguments presented above, it seems likely that CTWs communicate the effects of the 
Table 1. Correlation Between Band-Pass Filtered Bottom Temperature on $15-\mathrm{m}$ Isobath and Band-Pass Filtered Alongshore Pseudo-Stress at $27.5^{\circ} \mathrm{N}$ From NCAR/NCEP Reanalysis, Lagged by 3 Days $^{\text {a }}$

\begin{tabular}{lc}
\hline Time Band, Days & Correlation \\
\hline 3 to 7 & 0.13 \\
7 to 15 & 0.39 \\
15 to 30 & 0.50 \\
30 to 60 & 0.46 \\
60 to 120 & 0.45 \\
120 to 240 & 0.62 \\
240 to 400 & 0.73 \\
$>400$ & 0.12 (not significant) \\
\hline
\end{tabular}

${ }^{\mathrm{a}}$ All correlations are significant at the $95 \%$ level except that for periods greater than 400 days.

Mexican winds to the shores of Point Loma. However, it remains unclear how the waves affect the nearshore temperature. Some constraints can be put on the circulation driving the local temperature change if one assumes that alongisobath advection of temperature is negligible, despite the abrupt change in shelf width $5 \mathrm{~km}$ to the south and $15 \mathrm{~km}$ to the north (this assumption is relaxed later). Most revealing are the correlations between the stratification, the bottom temperature, and the near-surface temperature. From time series of temperature 0,18 and $26 \mathrm{~m}$ above the $33-\mathrm{m}$ isobath, and of their correlations, it can be seen that the temperatures are all positively or uncorrelated with each other, but not negatively correlated; thus when the bottom temperature rises, the temperatures above it either rise or stay the same, but do not decrease (Figures 7 and 8). Before mid-April, fluctuations in temperature are stronger near the bottom than higher in the water column, while after then the converse is true. Thus time series of the correlation between the bottom temperature and proxies for temperature stratification are negative before mid-April, and positive afterward (Figure 8). At the same time in mid-April that the correlation between the temperature stratification and the bottom temperature becomes positive and the correlation between the bottom and near-surface temperature becomes significantly greater than
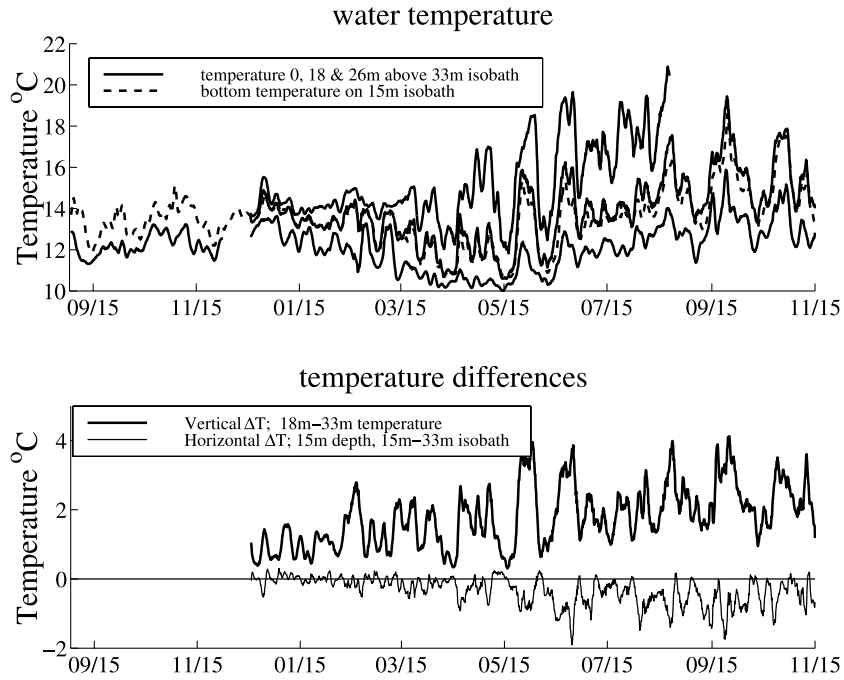

Figure 7. Time series of (top) temperature, which decreases monotonically with depth, and (bottom) temperature differences.
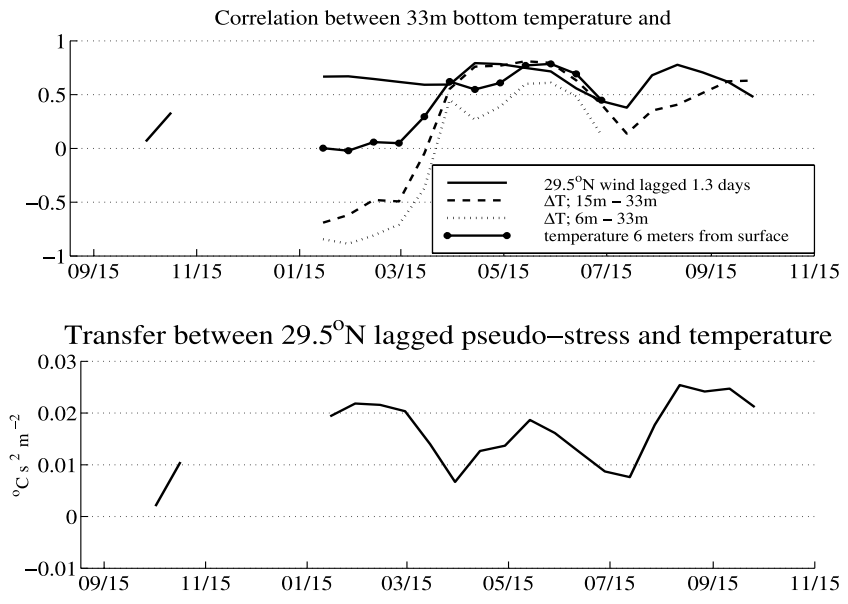

Figure 8. (top) Correlation between bottom temperature on $33-\mathrm{m}$ isobath and near-surface temperature or vertical differences in temperature over the $33-\mathrm{m}$ isobath. The correlation is taken over a 60-day detrended moving window of the data. Each correlation has about 12 degrees of freedom, so is significantly different from zero when $|r|>$ 0.5 at $P>0.95$. (bottom) The least-squares optimal transfer coefficient between the 1.3-day lagged alongshore pseudostress at $29.5^{\circ} \mathrm{N}$ and the bottom temperature on the $33-\mathrm{m}$ isobath computed over the same time window as the correlations.

zero, the horizontal temperature difference for water at a depth of $15 \mathrm{~m}$ between the 33- and $15-\mathrm{m}$ isobath becomes significantly negative as the nearshore waters become cooler than the offshore waters (Figure 7).

[26] These correlations can be rationalized in the limit of small alongshore advection of temperature with the aid of two cartoons of the density field (Figure 9), one from before mid-April when horizontal temperature gradients are small, and one for after mid-April when the temperature decreases shoreward and isotherms shoal upward toward the coast. On these two cartoons are superimposed three possible crossshelf current profiles which might cause cooling at depth: an onshore depth uniform velocity (A), an onshore velocity profile with stronger velocities near the surface (B), and an

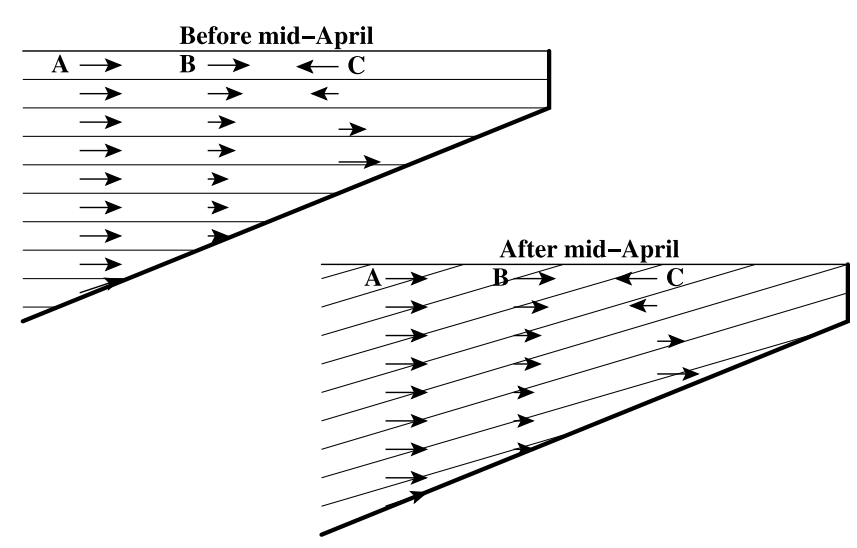

Figure 9. Cartoon of hypothetical temperature distribution before and after mid-April 2000, along with three possible cross-shelf current circulation patterns Pattern $\mathrm{C}$ is found to be most likely, at least after mid-April 2000. 
overturning, upwelling type circulation (C). Before midApril, before the isotherms tilt upward, all of the vertical distributions of cross-shelf currents will produce temperature change at the bottom that is uncorrelated with the little changing surface temperature, and all will produce a bottom temperature anti-correlated with stratification (e.g., cooling at the bottom increases the vertical temperature difference). But after mid-April, when the isotherms tilt upward, only the upwelling/downwelling circulation (C), with oppositely directed surface and bottom currents, can explain the positive correlation between both the bottom and near-surface temperature and the bottom temperature and the vertical temperature difference. Thus after mid-April, a cross-shelf upwelling/downwelling circulation is the most likely response of the ocean to remote winds, if alongshore advection can truly be neglected. Before mid-April, the circulation is less well constrained by the observations, but could also respond to the remote winds with an upwelling/downwelling circulation.

[27] The mid-April 1999 change in the isotherm tilt is associated with an increase upwelling favorable wind to the south. In an effort to see if this was a consistent relationship, the NCAR/NCEP winds at $27.5^{\circ} \mathrm{N}$ were compared to the cross-shelf temperature difference from late 1997 to the end of 2000, the longest record of cross-shelf temperature difference available. Unfortunately, this record has significant gaps due to instrument failure, and only totals just over 2 years in length. Of the several month or longer periods of small cross-shelf temperature gradient, three are associated with weaker Mexican winds. This is suggestive, but not significant. On timescales of less than a month, there is a significant correlation between upwelling favorable winds and stronger cross-shelf temperature gradients $(r=0.4)$ at a lag of several days.

\section{Possible Dynamics of CTW Forced Nearshore Circulation}

[28] Point Loma is a place of steep bottom slopes, strong stratification, and abruptly changing bathymetry (Figure 2), and it is unclear to what extent this amplifies or alters the temperature response to remote forcing, and thus to what extent the results presented here are applicable to the other shallow waters of the Southern Californian Bight and elsewhere. As a preliminary step toward understanding the importance of the bottom slope, stratification, and alongshore bathymetric variability, several mechanisms by which they could cause the CTWs to alter shallow water temperature will be examined.

[29] Unfortunately, the abrupt change in bathymetry makes it impossible to a priori predict the local alongshore pressure-gradients and currents associated with the remote winds. It is, at the least, unclear what relevance theoretical calculations of CTW modal structure would have in this region. The local strength of the remote forcing must then be judged by observations of local currents. Unfortunately, the alongshore velocity, $V$, is not measured as part of the San Diego kelp forest project, and prior observations of currents predate the availability of satellite winds. However, the 1996-1997 ONR Iwaves field program measured currents of $10 \mathrm{~cm} \mathrm{~s}^{-1}$ in 15 to $30 \mathrm{~m}$ of water about $5 \mathrm{~km}$ to the north of Point Loma, and 2 decades earlier, alongshore currents of the same standard deviation were measured at the same depths about $30 \mathrm{~km}$ to the north (J. Lerczak, personal communication, 2000) [Lentz and Winant, 1986]. In both cases, the mean was much less than the variance. Confusingly, Lentz and Winant [1986] found the currents to be dominated by remote forcing only during the winter and for depths greater than $30 \mathrm{~m}$. At $30 \mathrm{~m}$, local and remote forcing were of equal importance, and in depths less than $30 \mathrm{~m}$, local forcing dominated the currents in the winter. Nevertheless, in the following analysis, the alongshore currents will be scaled by $10 \mathrm{~cm} \mathrm{~s}^{-1}$. A more complete analysis must await the gathering of more data or the detailed modeling of the Point Loma region.

\subsection{Role of the Bottom Boundary Layer}

[30] In the 30- to 15-m-deep waters discussed above, the role of the bottom boundary layer would seem likely to dominate. However, for the time period analyzed here, the temperature stratification was nearly uniform across the water column and ranged from 0.1 to $0.3^{\circ} \mathrm{C} \mathrm{m}^{-1}$, so the buoyancy frequency $N$ ranged from 0.015 to $0.025 \mathrm{~s}^{-1}$. This strong stratification can, when advected across isobaths to form horizontal density gradients, cause the bottom boundary layer to "arrest" and bottom friction to become effectively zero [Trowbridge and Lentz, 1991]. Garrett et $a l$. [1993] argue that the time for this arrest to take place is approximately

$$
T_{\text {arrest }}=\frac{f^{3}}{N^{4}} \frac{V}{r}\left(\frac{\partial H}{\partial x}\right)^{-3},
$$

where $r$ is the drag coefficient of a linear drag law. Near Point Loma, $f=8 \times 10^{-5} \mathrm{~s}^{-1}$ and the bottom slope $\partial H / \partial x=$ $1.3 \times 10^{-2}$, so $T_{\text {arrest }}$ is always much less than an inertial period $\left(T_{\text {arrest }}<1000 \mathrm{~s}\right.$ for $\left.r=5 \times 10^{-4} \mathrm{~m} \mathrm{~s}^{-1}\right)$. Thus on a timescale comparable to an inertial period the bottom boundary layer will shut down. The horizontal density anomaly associated with this boundary layer arrest can be estimated by equating the pressure gradient associated with an alongshore geostrophic flow $V$,

$$
\frac{\partial P}{\partial x}=\rho_{0} f V
$$

with an equal but opposite pressure gradient caused by a bottom boundary layer of constant thickness and density anomaly $\Delta \rho$ over a bottom whose slope is $\partial H / \partial x$,

$$
\frac{\partial P}{\partial x}=g \Delta \rho \frac{\partial H}{\partial x} .
$$

When the pressure gradients are equal but opposite,

$$
\Delta \rho=\frac{\rho_{0} f V}{g}\left(\frac{\partial H}{\partial x}\right)^{-1},
$$

there is no pressure gradient at the bottom, and thus no flow. The temperature anomaly in the bottom boundary later associated with this arrest is

$$
\Delta T=\left(\frac{\partial \rho}{\partial T}\right)^{-1} \frac{\rho_{0} f V}{g}\left(\frac{\partial H}{\partial x}\right)^{-1},
$$


where $(\partial \rho / \partial T)^{-1}$ is $4.63^{\circ} \mathrm{C} \mathrm{m}^{3} \mathrm{~kg}^{-1}$ for $T=15^{\circ} \mathrm{C}$ and a salinity of 33 PSU. Scaling the alongshore velocity with $V \approx 10 \mathrm{~cm} \mathrm{~s}^{-1}$ gives a horizontal temperature anomaly of about $0.3^{\circ} \mathrm{C}$.

[31] The sign and the phase of the temperature signal caused by an arrested bottom boundary layer are appropriate; remote upwelling favorable wind anomalies drive upwelling favorable southward flow anomalies which drive local cooling on timescales longer than the arrest time. The magnitude of the effect is too small to explain the observed variation of temperature, however, by about a factor of about 10. The advection of temperature in the bottom boundary layer cannot explain the observed temperature signal, but perhaps the rapid shutdown of the bottom boundary layer is necessary for CTWs to affect shallow waters.

\subsection{Centrifugal and Inertial Upwelling}

[32] The flow curving around Point Loma might be expected to drive upwelling or downwelling not present along a straight coast. However neither of the mechanisms described below can explain the observations, thus are unlikely to dominate.

[33] Centrifugal upwelling, as described by Garrett and Loucks [1976], is the mechanism that concentrates tea leaves in the center bottom of a mug when the water is set spinning. The rotation of the water around the mug, or around Point Loma, exerts an outward centripetal force away from the center of rotation which is in cyclostrophic balance with a surface pressure gradient. Near the bottom, the flow is retarded by friction, the surface pressure gradient is not balanced by a centripetal acceleration, and there is a flow of water toward the center of rotation. This flow can be arrested by cross-isobath buoyancy transport, in the same way the Ekman transport is. But before the arrest, it would drive upwelling for either northward or southward currents around Point Loma. The relative importance of centripetal acceleration and centrifugal upwelling can be judged from the steady radial momentum equation, assuming that the radial velocity is negligible.

$$
\frac{u_{\theta}^{2}}{R}-f u_{\theta}=-\frac{1}{\rho} \frac{\partial P}{\partial r}
$$

where $u_{\theta}$ is the azimuthal velocity, corresponding to the alongshore velocity $v$, and $R$ is the radius of curvature of the isobaths. The ratio of the centripetal term $R^{-1} u_{\theta}^{2}$ to Coriolis term $f u_{\theta}$ is the Rossby number $\epsilon=u_{\theta} R^{-1} f^{-1}$, and will scale the relative importance of centripetal upwelling to the bottom boundary layer transports which would exist even in the absence of a curving coastline. The radius of curvature of the $20-\mathrm{m}$ isobath is about $8 \mathrm{~km}$, and as described above, typical alongshore velocity scales are about $10 \mathrm{~cm} \mathrm{~s}^{-1}$. The Rossby number is then about 0.15 ; thus the centrifugal acceleration is considerably less important than the Coriolis term, and hardly affects the cross-shelf transport. Thus centrifugal upwelling is too weak to explain the effect of CTWs on nearshore temperature.

[34] The curving flow around Point Loma can also cause an inertial overshoot of the alongshore current [e.g., Janowitz and Pietrafesa, 1982]. If the flow roughly follows the bathymetry (as seems reasonable for the small Rossby number found above), the relative vorticity associated with the curving isobaths will be $\epsilon f$, with an upwelling (southward) flow causing positive relative vorticity. A positive relative vorticity of $0.15 f$ would be associated with an offshore movement of the water to a depth $15 \%$ greater than it had along a straight coast, causing the bottom temperature to rise. The observed vertical stratification is roughly uniform in depth, varying from 3 to $8^{\circ} \mathrm{C}$ over $33 \mathrm{~m}$ of water, so a cross-isobath movement of a column of water would cause the bottom temperature there to rise by about $15 \%$ of this, or $0.2^{\circ}$ to $0.5^{\circ} \mathrm{C}$. This temperature change is smaller than that associated with CTWs in the data. It is thus unlikely that inertial effects explain the observed temperature changes. (Dale and Barth [2001] analyze strongly stratified flow around a point, and likewise find offshore motion for subcritical upwelling favorable flows.)

\subsection{Alongshore Advection}

[35] Neglected in the above discussion is the alongshore advection of temperature. It might seem plausible, for instance, that the CTW-driven alongshore currents might cause canyon-driven upwelling in the La Jolla canyon $20 \mathrm{~km}$ to the north, and then sweep the cold water to Point Loma [Allen, 2000]. The timescale of this advection, for a typical alongshore current of $10 \mathrm{~cm} \mathrm{~s}^{-1}$, would be about 2 days. This would delay the temperature response at Point Loma by about 2 days from the onset of upwelling in the La Jolla canyon. The only way this can be reconciled with the lags in the correlations in Figure 3 is by assuming that the flow at the La Jolla canyon responds instantly to the winds $300 \mathrm{~km}$ to the south at $30^{\circ} \mathrm{N}$. This seems implausible, so the advection of upwelled water from La Jolla canyon to Point Loma is unlikely to be responsible for the observed temperature changes at Point Loma. This logic does not rule out horizontal advection from a more nearby region of localized upwelling, but the likely nearby candidate for causing localized upwelling are the curving isobaths and shoreline near Point Loma found to be relatively unimportant in the last section.

[36] It is similarly unlikely that the observed temperature changes are caused by the alongshore advection of a largescale alongshore temperature gradient. Observations of the mean alongshore temperature difference over the $150 \mathrm{~km}$ north and south of Point Loma find that it varies from $4{ }^{\circ} \mathrm{C}$ in midsummer to $0^{\circ} \mathrm{C}$ in midwinter, with warmer water to the north [State of California, Research Committee, 1963]. Prior observations link upwelling favorable winds along the coast of Baja California to southward flows in the Southern Californian Bight [Lentz and Winant, 1986; Hickey et al., 2003]. If alongshore advection dominated, the southward flows driven by remote upwelling favorable winds would cause warming, contrary to the observations.

\subsection{Summary of the Role of Along-Shelf Bathymetric Variation and Advection}

[37] The analysis above suggests that the changes in temperature are directly caused by the CTWs and do not exist solely because of the along-shelf variations in bathymetry near Point Loma or the alongshore advection of temperature. The analysis does not rule out the enhancement of CTW signal by the bathymetric scattering of mode 
1 CTWs into higher modes with enhanced cross-shelf transport [Wilkin, 1988].

\section{Discussion and Conclusions}

[38] The nearshore temperature data from Point Loma and the along-shelf satellite winds from Baja California strongly indicate that variations in temperature on timescales from a week to a year at Point Loma are caused by mode 1 CTWs forced by winds hundreds of kilometers to the south of San Diego. At least part of the year, the waves force an overturning circulation in the nearshore, so the remote winds are forcing local upwelling and downwelling.

[39] Due to the scarcity of data, it is not possible to isolate and judge exactly the relative importance of the mechanisms which allow the CTWs to modify the nearshore temperature. However, simple scaling arguments suggest that temperature advection in the bottom boundary layer and inertial effects caused by the curving coastline are not dominant. The temperature fluctuations seem to be driven directly by the CTWs, though the effect of the CTWs may be amplified scattering into higher modes by alongshore variations in bathymetry [Wilkin, 1988]. Because the particular nature of the alongshore variation in bathymetry at Point Loma does not seem to be critical to the remote forcing of nearshore temperature, it seems likely that remote forcing will be important elsewhere in the nearshore regions of the Southern California Bight. North of Point Conception, local forcing becomes strong again and is almost certain to dominate.

[40] The cross-shelf transport caused by the remotely forced CTWs will be important not only to the physics but also for the biology of the nearshore regions. Besides the obvious effects of moving nutrients, pollution and plankton to and from the nearshore regions, the CTWs change the stratification, and not always in an intuitively obvious manner; for example, after mid-April 2000, nearbottom warming is associated with stronger stratification. Increased stratification will tend to suppress turbulence, simultaneously encouraging the growth of dinoflagellates and other turbulence-sensitive organisms and reducing the mixing-driven vertical flux of nutrients. Increased stratification also increases the phase speed of internal waves and bores, reducing the amount of dissipation they suffer across the shelf and increasing their amplitude in the nearshore [Pringle and Brink, 1999]. Thus the increased stratification will tend to increase the biological effects of the internal waves and bores, such as the cross-shelf transport of larvae [Pineda, 1999; Pineda and Lopez, 2002] and the episodic concentration of depth-keeping plankton [Lennert-Cody and Franks, 1999].

[41] The problem of remotely forced nearshore upwelling is far from closed. First and foremost, there need to be observations of nearshore and offshore currents at Point Loma simultaneously with direct observations of the remote winds to explicitly observe the flows leading to temperature change in waters of less than $30 \mathrm{~m}$ depth near Point Loma. Further theoretical work must wait on observations of temperature in shallow water elsewhere in the Southern California Bight, in regions of less variable bathymetry. If those observations show strong evidence of remotely forced temperature change, the next logical step is to model the nearshore dynamics of CTWs in strongly stratified shallow waters. If remote forcing is not strong elsewhere, then the modeling of the peculiar geometry of Point Loma would be the best next step.

[42] Acknowledgments. Mia Tegner gave me the temperature data, and pushed me to make sense of it. Without her, this paper would not exist, and to her it is dedicated. I wish she could have seen it. Kristin Riser took much of the temperature data, organized it, and answered my many questions about it. Many thanks are due to JPL and the QuikSCAT team for their marvelous data. Thanks also to Peter Franks for not objecting as I spent time on this project, instead of one even vaguely related to Georges Bank. John Kindle and Sergio Derada kindly provided me with the COAMPS winds in a convenient form, and Ken Brink and Steve Lentz pushed me to improve this paper with their comments. Sarah Gille patiently explained the strengths and flaws of several wind products. An anonymous reviewer greatly improved the paper by suggesting that I examine the longer timescales with more poorly resolved wind data sets. NCEP Reanalysis data provided by the NOAA-CIRES Climate Diagnostics Center, Boulder, Colorado, USA, from their Web site at http:// www.cdc.noaa.gov/. This work was funded through North Atlantic GLOBEC program grants NA76GP0176 and NA96OP0366 to Peter J.S. Franks from NOAA and OCE0219709 from NSF to James Pringle. Funding was also provided by the Leslie S. Hubbard Marine Program Endowment. This is GLOBEC contribution 359.

\section{References}

Allen, S. E., On subinertial flow in submarine canyons: Effect of geometry, J. Geophys. Res., 105, 1285-1297, 2000

Allen, J. S., and D. W. Denbo, Statistical characteristics of the large-scale response of coastal sea level to atmospheric forcing, J. Phys. Oceanogr., 14, 1079-1094, 1984.

Battisti, D. S., and B. M. Hickey, Application of remote wind-forced coastal trapped wave theory to the Oregon and Washington coasts, J. Phys. Oceanogr., 14, 887-903, 1984

Bograd, S. J., T. K. Chereskin, and D. Roemmich, Transport of mass, heat, salt, and nutrients in the southern California Current System: Annual cycle and interannual variability, J. Geophys. Res., 106, 9255-9275, 2001.

Brink, K. H., A comparison of long coastal trapped wave theory with observations off Peru, J. Phys. Oceanogr., 12, 897-913, 1982.

Brink, K. H., and J. S. Allen, On the effect of bottom friction on barotropic motion over the continental shelf, J. Phys. Oceanogr., 8, 919-922, 1978.

Chapman, D. C., Application of wind-forced, long, coastal trapped wave theory along the California coast, J. Geophys. Res., 92, 1798-1816, 1987.

Dale, A. C., and J. A. Barth, The Hydraulics of an Evolving Upwelling Jet Flowing around a Cape, J. Phys. Oceanogr., 31, 226-243, 2001.

Denbo, D. W., and J. S. Allen, Large-scale response to atmospheric forcing of shelf currents and coastal sea level off the west coast of North America: May-July 1981 and 1982, J. Geophys. Res., 92, 1757-1782, 1987.

Freilich, M. H., and R. S. Dunbar, The accuracy of the NSCAT 1 vector winds: Comparisons with National Data Buoy Center buoys, J. Geophys. Res., 104, 11,231-11,246, 1999.

Garrett, C. J. R., and R. H. Loucks, Upwelling along the Yarmouth shore of Nova Scotia, J. Fish. Res. Board Can., 33(1), 116-117, 1976.

Garrett, C., P. MacCready, and P. Rhines, Boundary mixing and arrested Ekman layers: Rotating stratified flow near a sloping boundary, Аnпu. Rev. Fluid Mech., 25, 291-323, 1993.

Hickey, B. M., Circulation over the Santa Monica-San Pedro Basin and shelf, Prog. Oceanogr., 30, 37-116, 1992.

Hickey, B. M., E. L. Dobbins, and S. E. Allen, Local and remote forcing of currents and temperature in the central Southern California Bight, J. Geophys. Res., 108, 3081, doi:10.1029/2000JC000313, 2003.

Hodur, R. M., The Naval Research Laboratory's Coupled Ocean/Atmosphere Mesoscale Prediction System (COAMPS), Mon. Weather Rev., $125,1414-1430,1997$.

Janowitz, G. S., and L. J. Pietrafesa, The effects of alongshore variation in bottom topography on a boundary current-Topographically induced upwelling, Cont. Shelf Res., 1(2), 123-141, 1982.

Kalnay, E., et al., The NCEP/NCAR 40-year reanalysis project, Bull. Am. Meteorol. Soc., 77, 437-471, 1996.

Kundu, P. K., Ekman veering observed near the ocean bottom, J. Phys. Oceanogr., 6, 238-242, 1976.

Lennert-Cody, C. E., and P. J. S. Franks, Plankton patchiness in highfrequency internal waves, Mar. Ecol. Prog. Ser, 186, 59-66, 1999.

Lentz, S. J., and C. D. Winant, Subinertial currents on the Southern California shelf, J. Phys. Oceanogr., 16, 1737-1749, 1986. 
Mitchum, G. T., and A. E. Clarke, The frictional nearshore response to forcing by synoptic scale winds, J. Phys. Oceanogr., 16, 934-946, 1986.

Pineda, J., Circulation and larval distribution in internal tidal bore warm fronts, Limnol. Oceanogr., 44, 1400-1414, 1999.

Pineda, J., and M. Lopez, Temperature, stratification and barnacle larval settlement in two Californian sites, Cont. Shelf Res., 22(8), 1183-1198, 2002.

Pringle, J. M., Enhancement of wind-driven upwelling and downwelling by alongshore bathymetric variability, J. Phys. Oceanogr., 32, 3101-3112, 2002

Pringle, J. M., and K. H. Brink, High-frequency internal waves on a sloping shelf, J. Geophys. Res., 104, 5283-5299, 1999.

State of California, Research Committee, California Cooperative Oceanic Fisheries Investigations: Atlas 1, Calif. Acad. of Sci., San Francisco, Calif., 1963.

Tegner, M. J., P. K. Dayton, P. B. Edwards, and K. L. Riser, Is there evidence for long-term climatic change in Southern California kelp forests?, Calif. Coop. Oceanic Fish. Invest. Rep., 37, 111-125, 1996.

Trowbridge, J. H., and S. J. Lentz, Asymmetric behavior of an oceanic boundary layer above a sloping bottom, J. Phys. Oceanogr., 21, $1171-$ 1185,1991
Wilkin, J. L., Scattering of coastal-trapped waves by irregularities in coastline topography, Ph.D. thesis, Mass. Inst. of Technol. and Woods Hole Oceanogr. Inst. Joint Program, Cambridge, Mass., 1988.

Winant, C. D., Comments on "The arrested topographic wave," J. Phys. Oceanogr., 9, 1042-1043, 1979.

Winant, C. D., and A. W. Bratkovich, Temperature and currents on the Southern California shelf: A description of the variability, J. Phys. Oceanogr., 11, 71-86, 1981.

Winant, C. D., and C. E. Dorman, Seasonal patterns of surface wind stress and heat flux, J. Geophys. Res., 102, 5641-5653, 1997.

J. M. Pringle, Department of Earth Sciences, University of New Hampshire, 142 Morse Hall, 39 College Street, Durham, NH 038243525, USA. (jpringle@cisunix.unh.edu)

K. Riser, Integrative Oceanography Division, Scripps Institution of Oceanography, University of California, San Diego, 9500 Gilman Drive, La Jolla, CA 92093-0227, USA. (kriser@ucsd.edu) 